\title{
BUNDLE ADJUSTMENT ACCURACY ASSESSMENT OF UNORDERED AERIAL DATASET COLLECTED THROUGH KITE PLATFORM
}

\author{
D. Abate ${ }^{1, *}$ and A. Murtiyoso ${ }^{2}$ \\ ${ }^{1}$ Science and Technology in Archaeology and Culture Research Center (STARC), \\ The Cyprus Institute, Nicosia, Cyprus \\ d.abate@cyi.ac.cy \\ ${ }^{2}$ Photogrammetry and Geomatics Group, ICube-TRIO Laboratory UMR 7357 INSA Strasbourg, France \\ arnadi.murtiyoso@insa-strasbourg.fr
}

\section{Commission II}

KEY WORDS: Bundle Adjustment, Camera Network, Kite Photography, Archaeological Documentation, DBAT

\begin{abstract}
:
The introduction into the commercial market of affordable and off-the-shelves Unmanned Aerial Systems (UAS), have lately boosted the mapping capabilities of archaeologists. Hardware solutions have been indeed supported by more accurate flight planning software allowing to increase the reliability of 3D models in terms of spatial resolution and geometric accuracy. However, during the last decades, aerial photography was mainly performed exploiting imaging sensors mounted on kites, balloons and poles. Although being an affordable and user-friendly solution, the use of these platforms did not allow the collection of images following an ordered data collection, hence introducing factors in the network design which could hamper the photogrammetric reconstruction. This study aims to assess the Bundle Adjustment (BA) accuracy and the reliability of the photogrammetric reconstruction by reprocessing various dataset collected over the UNESCO archaeological site of Khirokitia Vouni (Cyprus) using a commercial software and DBAT (Damped Bundle Adjustment Toolbox).
\end{abstract}

\section{INTRODUCTION}

\subsection{Context}

Thanks to the advancement in Unmanned Aerial Systems (UASs), the archaeological domain today largely benefits from airborne platforms for the documentation of excavated areas and sites (Campana, 2017). The latter, coupled with the development of Structure-from-Motion (SfM) algorithms (Nex and Remondino 2014), became indeed a standard tool for mapping purposes.

However, before the introduction of UAS, traditional aerial archaeological documentation was mainly realized through (i) classical expensive flight campaigns using light aircrafts, (ii) kites which for a long time represented a highly inexpensive and portable platforms that could accommodate a reasonable payload, with the main limitation represented by the dependency from no-wind or irregular-wind conditions; (iii) balloons which overcame the problems represented by no-wind conditions but conversely were not usable when the wind was too strong; (iv) poles which are a cost-effective and portable solution but they can usually only be used up to an altitude of $20 \mathrm{~m}$ above the ground. This study aims to address the usability and reliability of old dataset collected using a kite platform and assess the accuracy of the photogrammetric reconstruction, in particular considering the Bundle Adjustment (BA) metrics in an unordered camera network scenario. A crucial step in the photogrammetric workflow is indeed the determination of the position and attitudes of camera stations in the $3 \mathrm{D}$ space, solving the external

* Corresponding author orientation problem using image coordinates and the collinearity equations.

\subsection{Photogrammetric Network Design (PND)}

The Photogrammetric Network Design (PND) aims to help users to achieve the highest possible precision and reliability in the most economical manner. Ideally this process should be run through simulation, even though this is not always feasible especially in archaeological and heritage domain due to lack of expertise. The design process is usually concluded once a network reaches the desired accuracy, within the limit of cost and/or time (Hall, 1989; Fraser, 1996a; Olague and Mohr, 2002; Saadatseresht et al., 2004; Fraser et al., 2005). Theoretical analysis alone however is not sufficient since it is usually based on some simplifying assumptions and may not take into considerations all factors present in real case studies.

Many researches have analyzed the effects of (i) the base-line, (ii) the convergence angles of cameras, (iii) the number of intersection rays to an object point (OP), (iv) the number of measured points, and (v) orthogonal roll angles (Fraser 1996; Gruen and Beyer 2001; Remondino and Fraser 2006).

According to Fraser (1984) in a geometrically weak network, correlations may lead to instabilities in the least-squares adjustment for estimating the camera interior parameters, which in turn could undermine the use of the estimated results in the bundle adjustment solution. A significant overall accuracy enhancement can be achieved through the use of convergent imagery and related angle between the light rays. In El-Hakim et al., (2003) the authors highlighted that in a sequence of closely spaced images the effect was however partially compensated if the points were visible in different images (redundancy). 
Valtolini et al., (2006) observed that when the baseline between two images is increased, the computed theoretical precision of the object coordinates decreases until a stable value is reached. In (Fraser 1984) the analysis of an appropriate base-to-depth ratio is shown to be accompanied by an improved level of mean object point precision and enhanced reliability, ensuring a reconstruction that is less sensitive to noise and measurement errors. Deterioration in precision, principally in the $\mathrm{Z}$ coordinate, is the result of a less favourable ray intersection geometry occurring when a small base-to-distance ratio is established.

As presented in Luhmann et al., (2014), the achievable accuracy in object space of a photogrammetric measurement requires assessment against an independent external standard. However, the precision of the derived coordinates can be estimated approximately. The main parameters to take into account must comply with the PND and in particular with the: image scale (a function of camera-object distance and focal length); distance between cameras (stereo base); intersection geometry of the imaging configuration, as defined by the height to base ratio $(\mathrm{h} / \mathrm{b})$.

The above-mentioned parameters can be expressed as following, respectively for $\mathrm{X}$ and $\mathrm{Z}$ dimensions:

$$
\begin{aligned}
& s_{p x^{i}}=\frac{S Z \times b \times c}{h^{2}} \\
& s_{x^{i}}=\frac{S x}{m \times q}
\end{aligned}
$$

Where:

$$
\begin{aligned}
& S x=\text { object size } \\
& q=\text { network design factor } \\
& m=\text { scale (h/f) } \\
& s_{x^{i}}=\text { uncertainty of an image measurement }
\end{aligned}
$$

$$
\begin{aligned}
& S x=q \times m \times s_{x^{i}} \\
& S z=\frac{h^{2}}{b \times c} \times s_{p x^{i}}
\end{aligned}
$$

Where:

$$
\begin{aligned}
& S z=\text { object size } \\
& \mathrm{b}=\text { base line } \\
& S_{p x^{i}}=\text { measurement precision of the x-parallax } \\
& \mathrm{c}=\text { focal length } \\
& h=\text { distance object-camera }
\end{aligned}
$$

However, the formulas listed above assume a regular geometric network structure, of nominally constant image scale of which in aerial photogrammetry is linked to the altitude at which the image sensor is flying. A weak imaging geometry bearing (i) small intersection angles, (ii) small number of rays per object point (OP), and a poor interior orientation, can lead to a low reliability of the adjustment. Aside from hampering the key-points extraction and tie-points matching, it also affects the Ground Sampling Distance (GSD) which will not be computed uniformly.
Kite surveys, which were sometimes not even conceived for photogrammetric 3D mapping but only to create maps by exploiting image stitching techniques, are characterized by a very irregular distribution of camera stations and a very large-scale variation. The only way to get an accurate estimate of precision for the object points is hence to look at the a-posteriori standard errors from the BA process. For this purpose, the open source toolbox DBAT (Damped Bundle Adjustment Toolbox) for Matlab has been used to generate detailed photogrammetric network diagnostics to help assess the quality of the surveys computed initially in commercial software (Börlin and Grussenmeyer 2016; Murtiyoso et al., 2018). The assessment was performed by the careful examination of some of the BA metrics.

Different aerial datasets collected using commercial low-grade consumer cameras of the UNESCO archaeological site of Khirokitia Vouni (Cyprus) were collected.

\section{RELATED WORK}

\subsection{Kite Aerial Photography (KAP)}

For decades, Kite Aerial Photography (KAP) has been a reliable and widespread methodology for aerial reconnaissance in many different domains, including archaeology. Until the advent of motorized platforms, it was one of the most used solutions during excavations and surveys.

In Aber et al., (2002), the authors utilized kite aerial photography for diverse research and commercial applications including assessment of forests and wetlands, investigations of fluvial and glacial landforms, depiction of multiview-angle reflectance phenomena, and surveys of property and construction sites.

In Bitelli et al., (2004) a wide range of geomatic methodologies were experimented for archaeological mapping. The authors described the acquisition and processing steps of low-height aerial imagery to provide extensive mapping capabilities, using both semi-metric and non-metric cameras lifted by balloon and kites.

KAP have been also used for teaching purposes as a creative tool for geography field training and as a medium to approach the complexity of readily available geodata (Bogacki et al., 2005).

The Helikite system, a combination of both a helium balloon and kite wings, which allowed the acquisition of low-altitude aerial footage in very unstable wind conditions above a Roman quarry was described in Verhoeven et al., (2006). The authors highlighted the benefits for low-level photography represented the system during conditions in which a tethered balloon or a kite would fail to work properly.

In Fera and Geiger (2018) a GIS based system project on Sai Island in Northern Sudan is presented. During the campaigns, aerial photography of the environment was conducted for topographical landscape recording in form of high resolution orthophoto-mosaics and Digital Elevation Models (DEM) by KAP. 


\subsection{The Archaeological Site of Khirokitia Vouni (Cyprus)}

The site of Khirokitia Vouni was discovered in 1934 by Porphyrios Dikaios (Dikaios 1953) who, on behalf of the Department of Antiquities of Cyprus, conducted six field campaigns between 1936 and 1946. The exploration of the site was resumed in 1977 by a French mission sponsored by the Centre National de la Recherche Scientifique and the French Ministry of Foreign Affairs (Le Brun 1984, 1989, 1994, 2000, 2001; Daune-Le Brun, 2016; Daune-Le Brun and Le Brun, 2017).

Since its foundation, dated among the turn of the $7^{\text {th }}$ and $6^{\text {th }}$ century BCE, the village went through a sequence of phases. The hill chosen for the Neolithic settlement lies within a sharp bend of the Maroni river, which protects it on the north, east and southeast (Figure 1). When the site was occupied, the river had a more substantial extension than at present, as shown by recent research undertaken on the southeast flank of the settlement along the bank where several structures suffered from floods and shifts in the course of the riverbed.

This natural protection, however, didn't exist to the west where the village was open to the neighboring hills. In place of such natural defenses, a long, linear stone structure was built, crossing the settlement from north to south, providing artificial protection. When the settlement spread to the west onto previously unoccupied land, the same pattern was repeated, and the development was accompanied by the simultaneous building of a new boundary in the form of an impressive stone wall.

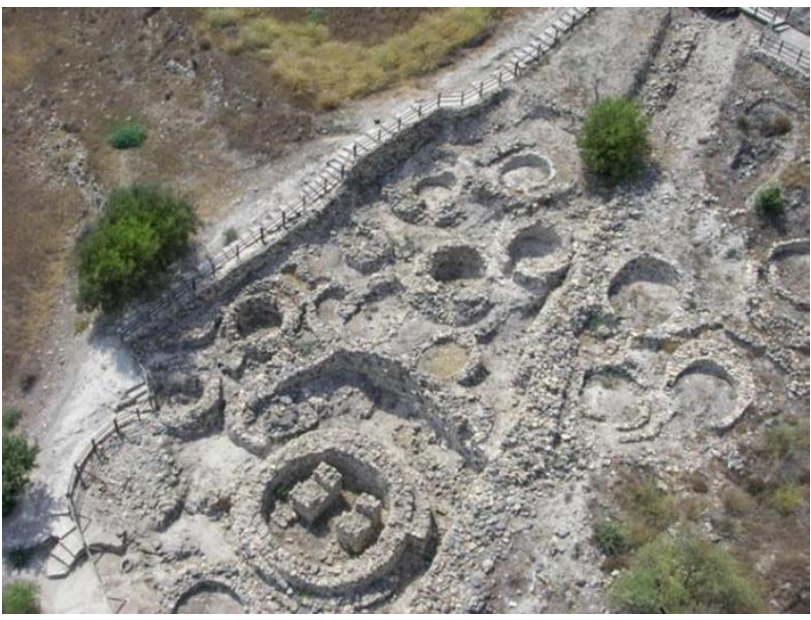

Figure 1. Khirokitia Vouni (Cyprus) archaeological site.

\section{METHODOLOGY}

The workflow followed in this study is summarized in Figure 2. After the initial camera's pose estimation, each project was reprocessed in DBAT and BA metrics analyzed and assessed.

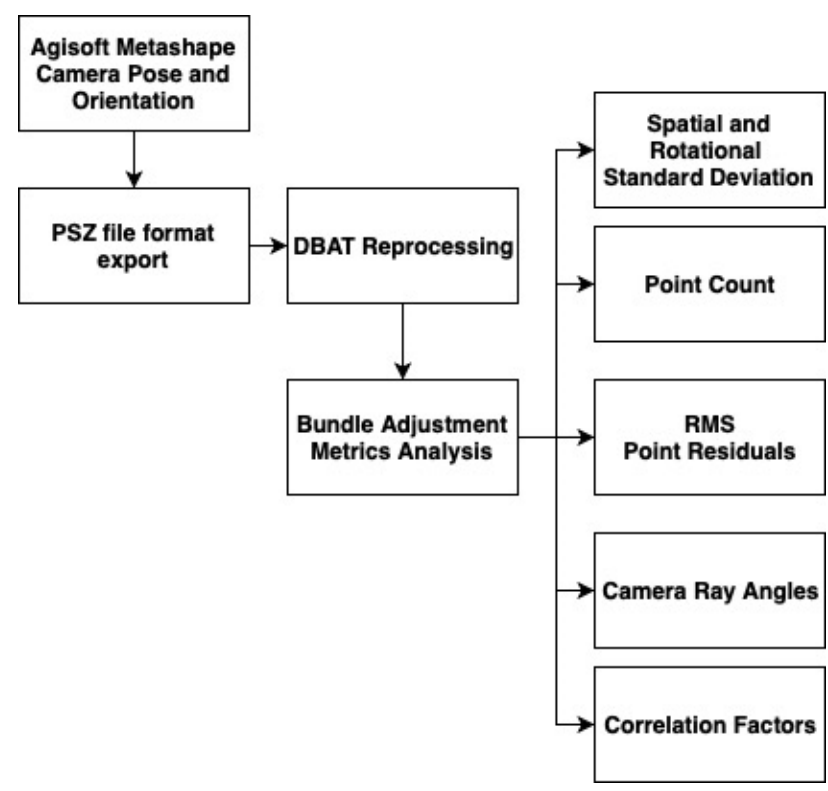

Figure 2. The workflow adopted in the project.

\subsection{Kite image dataset photogrammetric reconstruction}

The image-based modelling reconstruction of the UNESCO site of Khirokitia Vouni was created using four different datasets, collected specifically during the excavation seasons 2007, 2009, 2011, 2013. Four consumer grade digital compact cameras, not exceeding $13 \mathrm{Mpx}$ resolution were used (Table 1).

\begin{tabular}{|c|c|c|c|}
\hline $\begin{array}{c}\text { Camera } \\
\text { Model }\end{array}$ & $\begin{array}{c}\text { Sensor } \\
\text { (width- } \\
\text { height mm) }\end{array}$ & $\begin{array}{c}\text { Number of } \\
\text { Images }\end{array}$ & $\begin{array}{c}\text { Max } \\
\text { Resolution }\end{array}$ \\
\hline $\begin{array}{c}\text { Pentax } \\
\text { Optio W30 } \\
\text { RICOH }\end{array}$ & $\begin{array}{c}5.75 \times 4.32 \\
\mathrm{~mm} \mathrm{CCD}\end{array}$ & 277 & $7.40 \mathrm{Mpx}$ \\
\hline $\begin{array}{c}\text { Caplio } \\
\text { GX 100 }\end{array}$ & $\begin{array}{c}7.31 \times 5.49 \\
\mathrm{~mm} \mathrm{CCD}\end{array}$ & 104 & $10.30 \mathrm{Mpx}$ \\
\hline RICOH & $\begin{array}{c}23.6 \mathrm{~mm} \mathrm{x} \\
15.7 \mathrm{~mm} \\
\mathrm{CMOS}\end{array}$ & 73 & $12.90 \mathrm{Mpx}$ \\
\hline RXR A12 & $\begin{array}{c}23.6 \mathrm{~mm} \mathrm{x} \\
15.7 \mathrm{~mm} \\
\text { CMOS }\end{array}$ & 251 & $12.90 \mathrm{Mpx}$ \\
\hline GXR A12 & \multicolumn{1}{|l}{} \\
\hline
\end{tabular}

Table 1. Camera sensors list.

The effect of image resolution on the computed 3D object coordinates was investigated in Nakada and Chikatsu (2003). The author examined the variation of accuracy observing analyzing the sensors resolution in terms of pixel. In El-Hakim et al., (2003) the authors used small and large targets to assess the relationship between accuracy and image resolution on the $\mathrm{Z}$ coordinate using camera sensors ranging from 1.5 to 14 megapixels. 

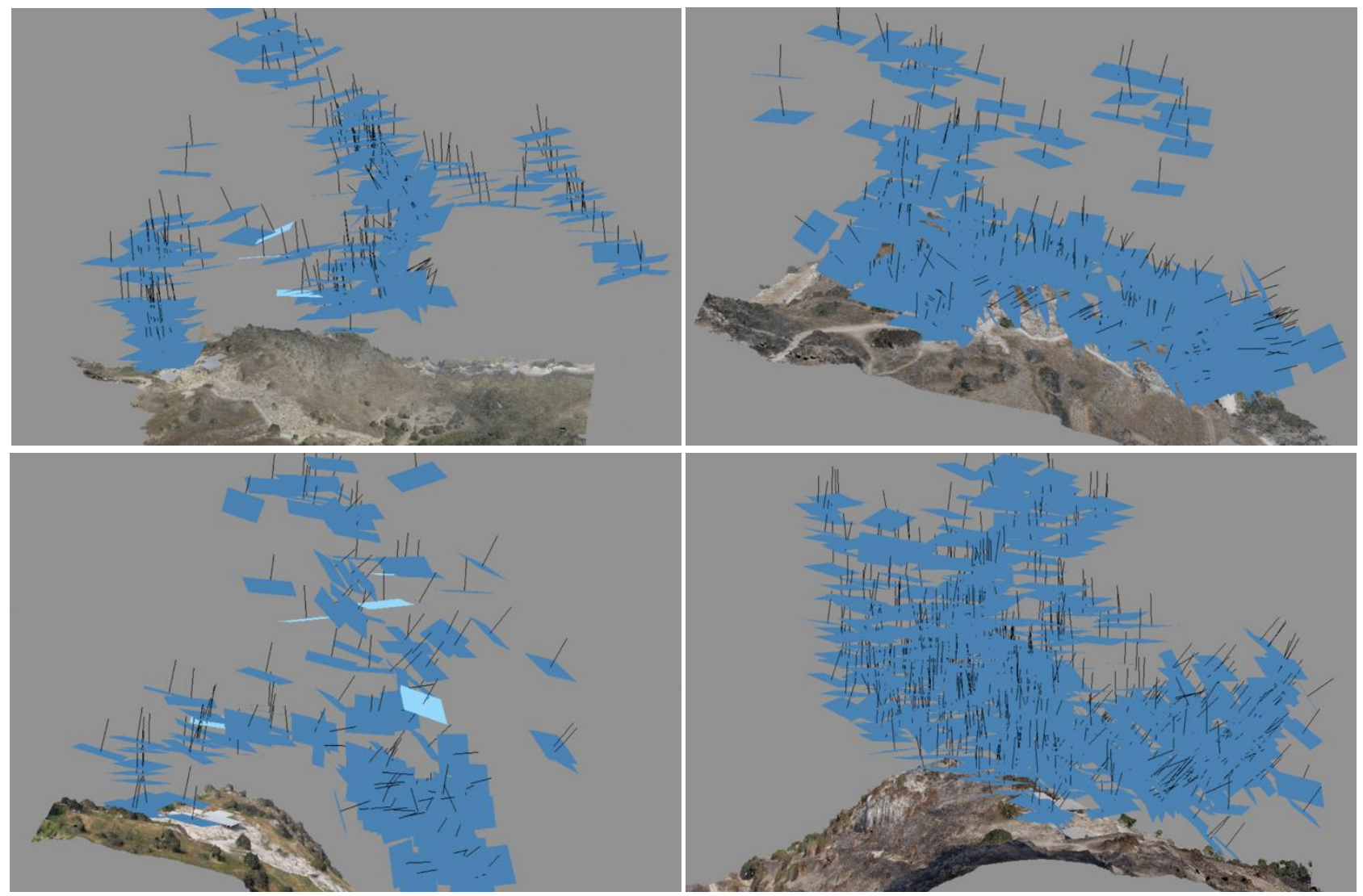

Figure 3. Khirokitia Vouni, kite aerial datasets, estimated camera poses and orientation, 2007 (top left), 2009 (top right), 2011 (bottom left), 2013 (bottom right).

The data available were nadir and oblique images acquired with different tilt angles and at different heights. Large displacements in off-nadir views and variation of radiometry in an image block (the data capture was performed during different day and time conditions) are parameters which can decrease the accuracy of the photogrammetric reconstruction.

During the data collection step, the devices were set in auto-mode therefore the shutter speed and aperture parameters were determined automatically depending on the amount of light that goes into the camera and the ISO.

Starting from the estimated camera poses and orientation, it was possible to visually assess the un-ordered flight plan resulting from the kite survey (Figure 3). The main features highlighted were:

- big variation in altitude $(h)$;

- small base to depth ratio $(b / d)$.

The statistic generated by Agisoft Metashape software didn't provide any specific hint concerning the camera network created from such an irregular data collection step, also due to the lack of a proper topographic survey. The 2007 dataset produced a Ground Control Pount (GCP) error of $1.7 \mathrm{~cm}$; however only four GCPs were used and this value must therefore be treated with care. Likewise, the 2009 dataset presented a very low error of 0.8 $\mathrm{cm}$ in Metashape from six GCPs.
This may be an indication of over-estimation of the precision by Metashape, considering the centimetric ground sampling distance. The 2011 dataset generated a modest $7.9 \mathrm{~cm}$ of GCP RMS error, while the 2013 dataset gave the value of $6.3 \mathrm{~cm}$. All of these values were obtained from few GCP points and may not necessarily reflect the overall quality of the respective projects; hence the motivation in using DBAT in this paper to generate more useful metrics to assess their quality.

In principle, flight planning refers to the initial determination of flight geometry, given the area of interest and the required endproduct, and thus the desired accuracy. In the case of traditional nadir imagery, the parameters that are optimized are the flying height, the camera with its optics and the overlap pattern. (Förstner 1985; Ackermann 1992, Kraus 1997, 2007). Lately, oblique imaging started to be employed for different application fields (Remondino and Gerke 2015, Rupnik et al., 2015), especially when information about vertical structures are required.

Although not relevant for this study, a dense 3D reconstruction via a pixel-based image matching algorithm was applied. This was performed using the first-level image pyramid, corresponding to the original full image resolution (Figure 4). 


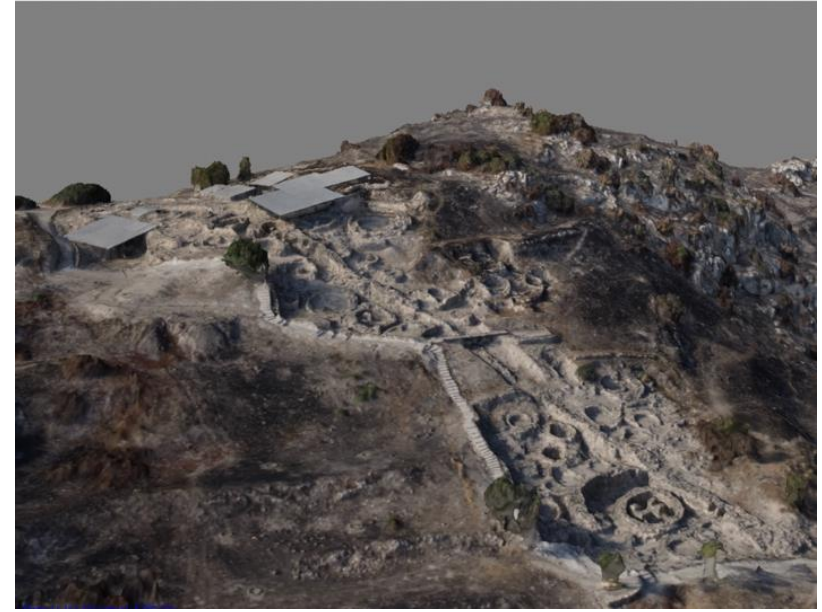

Figure 4. Khirokitia Vouni, Dense Image Matching, 2013 dataset.

\subsection{Bundle Adjustment Assessment}

All image datasets were initially processed in Agisoft Metashape software following the standard workflow. Although being one of the most used commercial software for image-based 3D modeling, Agisoft Metashape is still considered, amongst others, a blackbox solution which provides limited knowledge of the BA metrics. Due to this reason, the Khirokitia image datasets were reprocessed in DBAT and the results were analyzed.

DBAT outputs allowed to have a meaningful insight on the BA parameters computed, allowing the detection of potential errors or outliers in the project, and serving as a quality control tool for a more accurate and reliable a-posteriori photogrammetric reconstruction. (Figure 5).

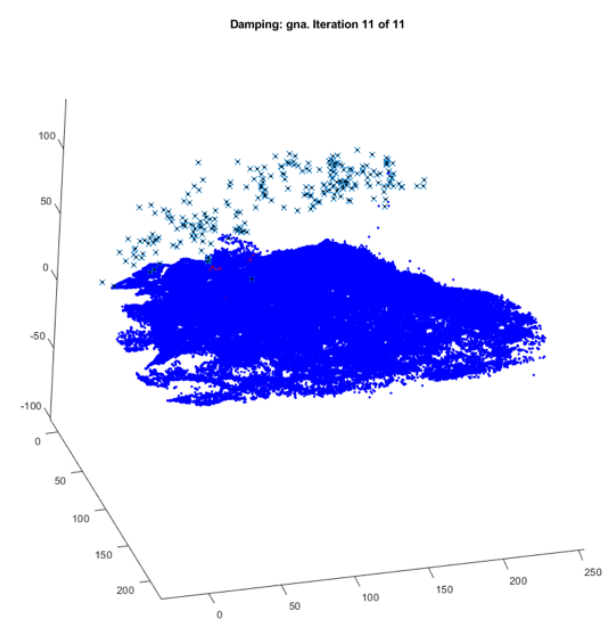

Figure 5. DBAT dataset 2013, Camera External orientation and sparse point cloud (tie-points).
All datasets show a high correlation values between the different camera calibration parameters computed within the bundle adjustment. This may depend on faulty physical assumptions due to the unordered camera network, as well as the lack of strong convergence. High correlations can result in a weak, or even false, calibration solution. Even worse, the calibration results might be block-dependent (Tang and Fritsch, 2013).

Despite showing an improvement from 2007 to 2013 datasets, the self-calibration procedure (Clarke and Fryer, 1998) may not be sufficient to properly calibrate the cameras interior parameters (Luhmann et al., 2006). The latter can indeed be reliably calculated if the image configuration and distribution of object points are well chosen (Luhman et al., 2014). Another reason which could have affected the weak camera self-calibration can be observed in the camera geometry changing over the acquisition period due to the auto shooting mode (i.e. auto-focus; auto-zoom), and the lens distortion of low-grade cameras.

Table 2 summarizes the high correlation factors computed by DBAT among the different flights.

\begin{tabular}{|c|c|c|c|}
\hline $2007(\%)$ & $2009(\%)$ & $2011(\%)$ & $2013(\%)$ \\
\hline K1-K2: 95.3 & K2-K3: 98 & K2-K3: 98.2 & K1-K2: 95.1 \\
K2-K3: 98.3 & & & K2-K3: 98.4 \\
\hline
\end{tabular}

Table 2. Correlation factors.

The dissimilarity in the flight altitude, observed in different magnitude in almost all datasets, appear to have a direct effect on the Spatial and Rotational Standard Deviation (SD), Point Count and Ray Angles of each photogrammetric reconstruction.

The image scale variations (depending on the image tilt, sensor size, focal length and flying height), can indeed hamper large aerial block data image-based modelling.

This correlates with the low point count for those particular images, and sometimes also with a decrease in the camera ray angles (Figure 6).

The correlation between the number of tie points in an image and the precision of its exterior orientation parameters is expected, as fewer observations will generate lower precision due to a lower redundancy. In addition, the image coverage correlates with the number of tie points in the images.

The correlation between the number of tie points in an image and the precision of its exterior orientation parameters is expected, as fewer observations will generate lower precision due to a lower redundancy. In addition, the image coverage correlates with the number of tie points in the images.

The assessment of the four analyzed datasets, shows that the 2013 image block achieve the best result in terms of BA metrics. The RMS point residuals, although still in the order of $10 \mathrm{~cm}$ is the lowest among all the results obtained reprocessing the project through DBAT. 

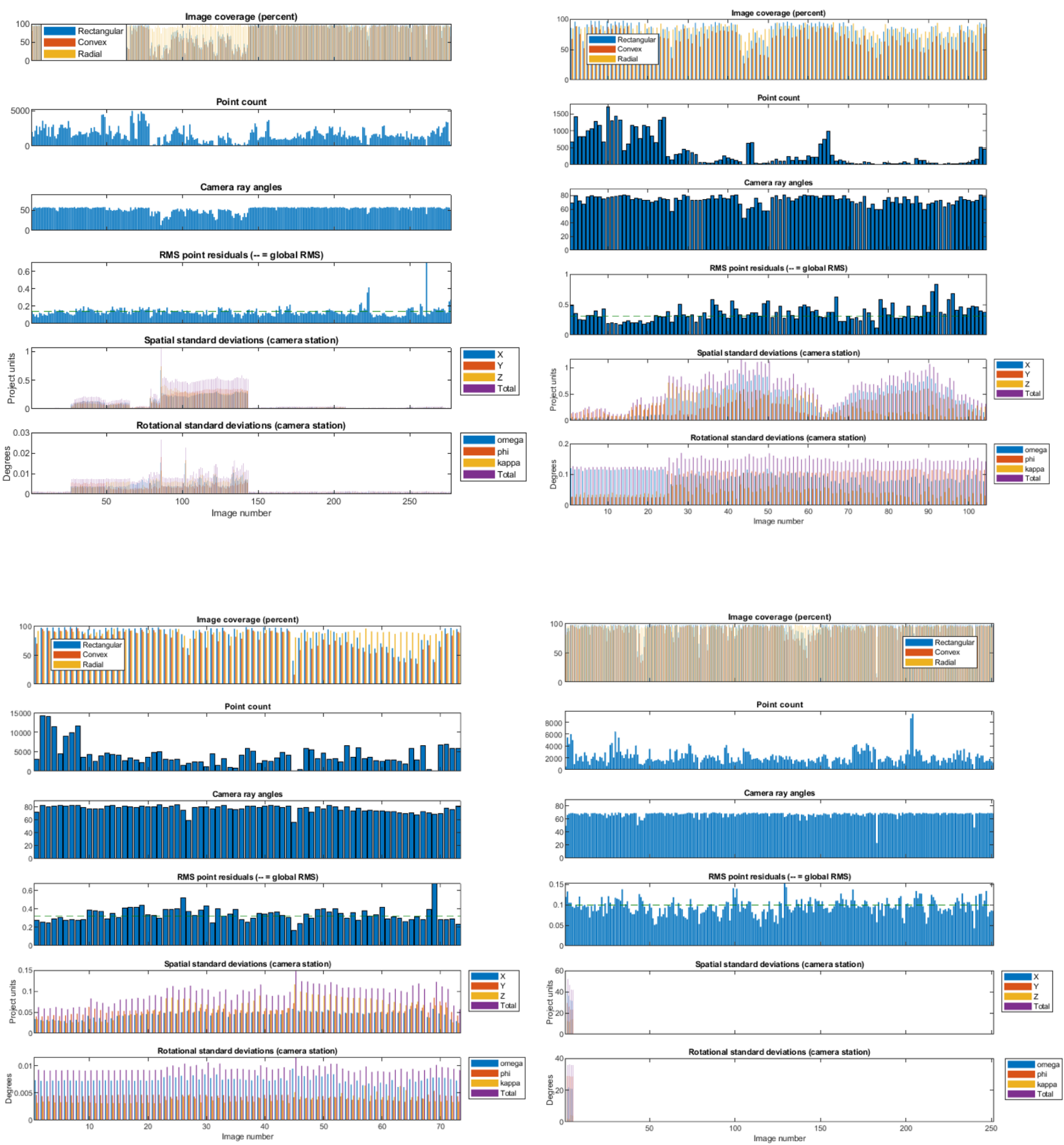

Figure 6. DBAT Bundle adjustment metrics, 2007 (top left), 2009 (top right), 2011 (bottom left), 2013 (bottom right).

The different flight altitude of some camera stations reflects clearly in the point count and camera ray angles analysis.

Although DBAT highlighted a set of images for the 2013 flight which contain high Spatial and Rotational Standard Deviation errors, this, compared with the other statistics, can be interpreted as an outlier produced by Agisoft Metashape software.

\section{CONCLUSIONS}

The main aim of this study was to analyse and assess the usability and reliability of old image aerial datasets collected through kites for 3D photogrammetric reconstruction. Four multitemporal group of images acquired at the archaeological site of Khirokitia Vouni (Cyprus) have been used. 
All data have been initially run using the commercial software Agisoft Metashape, until the determination of the camera's pose was achieved, and then reprocessed using DBAT to obtain analytical metrics of the Bundle Adjustment.

Due to the unordered camera network, the overall DBAT statistics are able to provide useful indications, highlighting the parts of the dataset (i.e. which images) which most likely contribute to weaken the photogrammetric $3 \mathrm{D}$ reconstruction.

The main risk in processing aerial dataset, collected without following an a-priori designed flight plan and using blackbox commercial solutions, is that the user is not provided with enough and meaningful information and parameters for the estimation and the precision of the object points. In this project, DBAT was instead able to highlight the blocks of images which presented the highest errors in terms of standard deviation, point count and ray angles in the Bundle Adjustment process. As expected, the images collected at different altitude weakened the camera network and the overall 3D reconstruction.

In conclusion it can be affirmed that, although commercial software are able to produce detailed 3D models processing old images datasets collected using different platforms (i.e. kite, ballons, etc), an external assessment of the photogrammetric parameters is needed to evaluate the geometric reliability of the end-products.

\section{ACKNOWLEDGEMENTS}

The authors wish to thank Dr Odile Daune-Le Brun (CNRS) for the permission to use to the aerial image database collected during the French archaeological missions in Khirokitia.

\section{REFERENCES}

Aber, J. S., Aber, S. W., Pavri, F., 2002. Unmanned small- format aerial photography from kites for acquiring large scale, highresolution, multiview-angle imagery. ISPRS Archives, Pecora 15/Land Satellite Information IV/ISPRS Commission I/FIEOS, Denver, CO, USA.

Ackermann, F., 1992. Kinematic GPS control for photogrammetry Photogramm. Record, 14 (80), pp. 261-276.

Bitelli, G., Girelli, V., Tini, M. A., Vittuari, L., 2004. Low-height aerial imagery and digital photogrammetrical processing for archaeological mapping. International Archives of Photogrammetry, Remote Sensing and Spatial Information Services, pp. 498-504.

Bogacki, M., Malkowski, W., Misiewicz, K., 2008. Kite aerial photography (KAP) as a tool for completing GIS models. Ptolemais (Libya) case study. Lasaponara, R., Masini, N., Aracne (Eds.), Remote Sensing for Archaeology and Cultural Heritage Management. Proceedings of the 1st International EARSeL Workshop, CNR, Roma, pp. 329-332.

Börlin, N. and Grussenmeyer, P., 2016. External verification of the bundle adjustment in photogrammetric software using the damped bundle adjustment toolbox, Int. Arch. Photogramm. Remote Sens. Spatial Inf. Sci., XLI-B5, pp. 7-14, https://doi.org/10.5194/isprs-archives-XLI-B5-7-2016, 2016.

Campana, S., 2017. Drone in Archaeology: State-of-the-art and Future Perspective. In: Archaeological Prospection, Volume 24, Issue 4, pp. 275-296.
Clarke, T.A., and Fryer, J.G., 2013. The Development of Camera Calibration Methods and Models. Photogrammetric Record, 16(91), 51-66 (1998)

Daune-Le Brun O., 2016. Le numérique pas à pas : la fouille du site néolithique de Khirokitia (Chypre). In : Bellon E., Rohfritsch A., Archives de l'archéologie française à l'étranger. Les Nouvelles de l'archéologie 145.

Daune-Le Brun O., and Le Brun, A., 2017. 'Singing in the rain': Khirokitia (Cyprus) in the second half of the seventh millennium cal B.C. In P.F. Biehl and O.P. Nieuwenhuyse (eds.), Climate and Cultural Change in Prehistoric and the Near East. Institute for European and Mediterranean Archaeology Proceedings 6, pp. 153-168. Albany: State University of New York Press.

Dikaios, P., 1953. Khirokitia. Monograph of the Department of Antiquities, Government of Cyprus 1, Oxford University Press.

El-Hakim, S. F., Beraldin, J. A., Blais, F., 2003. Critical factors and configurations for practical image-based 3D modeling. Proceedings of 6th Conference Optical 3D Measurements Techniques. Zurich, Switzerland. Vol. II, pp 159-167.

Fera, M., and Geiger, C., 2018. Image Based Modelling and Kite Aerial Photography on Sai Island. In: From Microcosm to Macrocosm. Individual Households and Cities in Ancient Egypt And Nubia, pp. 127-134.

Förstner, W., 1985. The Reliability of Block Triangulation, Photogrammetric Engineering and Remote Sensing, Vol. 51, pp. 1137-1149.

Fraser, CS., 1982. On the use of non-metric cameras in analytical non-metric photogrammetry. International Archives of Photogrammetry and Remote Sensing, 24(5), pp. 156-166.

Fraser, C.S., 1984. Network Design considerations for nontopographic photogrammetry. Photogrammetric engineering and remote sensing, Vol. 50, No. 8, pp.1115-1126.

Fraser, C. S., 1996a. Network design. Chapter 9 in Close Range Photogrammetry and Machine Vision (Ed. K. B. Atkinson). Whittles, Caithness, pp. 256-281.

Fraser, C.S., 1996b. Network design. In Atkinson (Ed.), Closerange photogrammetry and machine vision, pp. 256-282.

Fraser, C. S., Woods, A. and Brizzi, D., 2005. Hyper redundancy for accuracy enhancement in automated close-range photogrammetry. Photogrammetric Record, 20(111), pp. 205217.

Gruen, A., and Beyer, H.A., 2001. System calibration through self-calibration. In Gruen \& Huang (Eds.), Calibration and orientation of cameras in computer vision (Vol. 34). Springer Berlin Heidelberg: Springer Series in Information Sciences, pp. 163-194.

Hall, C. J., 1989. Design procedures for close range photogrammetry in surveying and land information. M.Sc. Thesis, The University of Melbourne, Melbourne.

Kraus, K., 1997. Photogrammetry - Advanced Methods and Applications. Dümmler Verlag. 
Kraus, K., 2007. Photogrammetry: Geometry from Images and Laser Scans. Walter de Gruyter.

Le Brun, A., 1984. Fouilles récentes à Khirokitia (Chypre) 19771981. Etudes néolithiques, Edition Recherche sur les Civilisations, Mémoire $N^{\circ} 41$. Paris.

Le Brun, A., 1989. Fouilles récentes à Khirokitia (Chypre) 19831986. Etudes néolithiques, Edition Recherche sur les Civilisations, Mémoire $N^{\circ} 81$. Paris.

Le Brun, A., 1994. Fouilles récentes à Khirokitia (Chypre) 1988 1991. Etudes néolithiques, Edition Recherche sur les Civilisations. Paris.

Le Brun, A., 2000. A propos des sites néolithiques chypriotes à limites aménagées. Acts of the third International Congress of Cypriot studies. Nicosie, Chypre, pp. 203-217.

Le Brun, A., 2001. At the other end of the sequence: The Cypriot aceramic Neolithic as seen from Khirokitia. - S. Swiny (ed.). The Earliest Prehistory of Cyprus from Colonization to Exploitation. Caari Monograph Series, 5. Boston, pp. 109-118.

Luhmann, T., Robson, S., Kyle, S. and Harley, I., 2006. Close Range Photogrammetry. Whittles, Scotland, UK.

Luhmann, T., Robson, S., Kyle, S., Boehm, J., 2014. Close-range photogrammetry and 3D imaging, pp. 141-143.

Murtiyoso, A., Grussenmeyer, P., Börlin, N., Vandermeerschen, J., Freville, T., 2018. Open Source and Independent Methods for Bundle Adjustment Assessment in Close-Range UAV Photogrammetry, Drones, 2, 3.

Nakada, R., and Chikatsu, H., 2003, Generating 3D Model of "Meguro Residence" using Digital Armature Camera, International Archives of Photogrammetry and Remote Sensing (CD-Rom), Vol.XXXIV-5/W10, ISSN 1682-1777, Vulpera.

Nex F., and Remondino, F., 2014. UAV for 3D mapping applications: a review. Applied Geomatics, Vol.6(1), pp. 1-15, DOI $10.1007 / \mathrm{s} 12518-013-0120-\mathrm{x}$.

Olague, G. and Mohr, R., 2002. Optimal camera placement for accurate reconstruction. Pattern Recognition, 35(4), pp. 927-944.

Remondino, F, and Fraser, C.S., 2006. Digital camera calibration methods: considerations and comparisons. International Archives of Photogrammetry, Remote Sensing and Spatial Information Sciences, 36 (Part 5), pp. 266-272.

Remondino, F., Gerke, M., 2015. Oblique Aerial Imagery - A Review. Proc. Photogrammetric Week 2015, D. Fritsch (Ed.), pp. $75-83$

Rupnik, E., Nex, F., Toschi, I., Remondino, F., 2015. Aerial multi-camera systems: Accuracy and block triangulation issues. ISPRS Journal of Photogrammetry and Remote Sensing, Volume 101, pp. 233-246.

Saadatseresht, M., Fraser, C. S., Samadzadegan, F. and Azizi, A., 2004. Visibility analysis in vision metrology network design. Photogrammetric Record, 19 (107), pp. 219-236.

Tang, R., and Fritsch, D., 2013. Correlation Analysis of Camera Self- Calibration in Close Range Photogrammetry. The
Photogrammetric Record 28(141), pp. $\quad 86-95$ DOI: 10.1111/phor.12009.

Verhoeven, G., Loenders, J., Vermeulen, F., and Docter, R., 2009. Helikite aerial photography (HAP) - a versatile means of unmanned, radio-controlled, low-altitude aerial archaeology, Archaeological Prospection, 16(2), pp. 125-38.

Verhoeven, G., Taelman, D., Vermeulen, F., 2012. Computer vision-based orthophoto mapping of complex archaeological sites: the ancient quarry of Pitaranha (Portugal-Spain). Archaeometry 54, 6, pp. 1114-1129.

Voltolini, F., Remondino, F., Pontin, M., Gonzo, L., 2006. Experiences and considerations in image-based-modeling of complex architectures. International Archives of Photogrammetry, Remote Sensing and Spatial Information Sciences, Vol. XXXVI, part 5, pp. 309-314. 